\title{
Homework in function of formative assessment of students' achievements in teaching the Macedonian language in the Republic of Macedonia
}

\author{
Januševa, Violeta $\$ \\ University “Sv. Kliment Ohridski”, Republic of Macedonia (violetajanuseva@gmail.com) \\ Pejčinovska, Milena \\ University "Sv. Kliment Ohridski”, Republic of Macedonia (milena pejcinovska@yahoo.com) \\ Talevski Dimitrija, Jove \\ University “Sv. Kliment Ohridski”, Republic of Macedonia (jovetalevski@yahoo.com) \\ Merkovska, Marija \\ University “Sv. Kliment Ohridski”, Republic of Macedonia (mariija bt 90@yahoo.com)
}

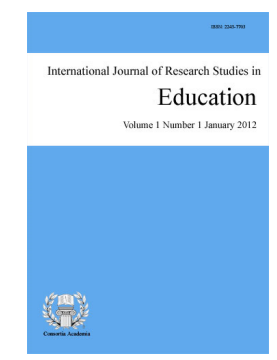

ISSN: 2243-7703 Online ISSN: 2243-7711

OPEN ACCESS

\section{Abstract}

The purpose of this paper is: to investigate whether the Macedonian language curriculum and textbooks sufficiently emphasize the importance of homework; to reveal whether homework causes interest among students and contributes to the development of creativity and research; to find out whether the type of homework in the textbooks allows students to develop higher cognitive processes and teachers to direct the learning and give constructive feedback to improve the quality of the teaching process and students' achievement. The research has a qualitative paradigm (content analysis) and descriptive design. Analysis and synthesis are methods for data processing and gaining scientific conclusions. The analysis shows the need of revision of the Curriculum and Textbooks because they do not emphasize the significance of homework sufficiently. All of the assignments are alike, written and individual, continue the work from the lesson in class, present application of the gained knowledge and reflect the understanding and application levels of Bloom's Taxonomy. Aside from not being creative and interesting for the students, the assignments do not encourage the development of creativity, imagination and research potential. They contribute neither to the development of higher cognitive processes of students nor provide grounds for targeting learning and constructive feedback.

Keywords: homework assignments; formative assessment; students' achievements; Macedonian language; Republic of Macedonia 


\section{Homework in function of formative assessment of students' achievements in teaching the Macedonian language in the Republic of Macedonia}

\section{Introduction}

Formative assessment is a new paradigm of assessing in Macedonia directed towards improving the learning among students, especially for developing higher cognitive processes: analysis, synthesis, and evaluation. It is a developmental assessment by which frequent and interactive evaluation of students' achievement is implemented. It takes into account the learning needs of students and adapts teaching methods to the needs and abilities of the student. This assessment affects the objectivity of the assessing of student's achievements to a large extent, namely students get a realistic picture of their achievements in teaching. They perceive parts of their learning difficulties and shortcomings so they can promptly work to improve the learning process and to gain knowledge of the teaching process in an efficient and effective way. Formative assessment allows students to qualify for their own assessment and evaluation of achievements. It builds moral character of students, develops democracy in the classroom, sets a balance between the role of teacher and student, and above all it develops the positive characteristics of the students' personality. Formative assessment can be implemented through various activities. Homework is considered as a significant tool for formative assessment.

Many researchers stress the important role of the homework assignments for the formative assessment. Therefore, the purpose of the paper is: to investigate whether the Macedonian language curriculum and textbooks sufficiently emphasize the importance of homework; to reveal whether homework causes interest among students and contribute to the development of creativity and research; to find out whether the type of homework textbooks allows students to develop higher cognitive processes, and allows teachers to direct learning and give constructive feedback.

\section{Results from previous research}

Formative assessment is differentiated, which means it is directed towards the achievement of each student. The purpose of formative assessment is not the assessment with grades, but guiding the student's learning. Effective and efficient formative assessment of students assumes that students are familiar with learning objectives and that timely formative and corrective feedback is provided (Januševa \& Talevski Dimitrija, 2015, p. 15). The professional literature highlights the importance of homework for the application of students' knowledge and exercising habits necessary for gaining further knowledge (Andrilović \& Čudina, 1985; Vilotijević, 1999; Stevanović, 2001; Kamčevska, 2006). But so far in Macedonia there is no research on the role of homework in the formative assessment of students. The only document which stresses the role of the homework assignments for formative assessment in the Republic of Macedonia is the Guidance.

In order to improve the quality of the teaching process and acquire knowledge, Bureau for Development of Education prepares didactic guidelines concerning homework assignments. From the title of the Guidance (Guidance on the form of preparation, planning, setting, implementation and monitoring of homework for primary school pupils), as well as its contents, we recognize that the Guidance provides guidelines for homework assignments that are prepared by the teacher, and not for those assignments found on the pages of the Textbook, which are prepared by the authors of the textbook. This is a clear indicator that teachers are expected, though they can use homework from the textbook, to prepare their own homework, which certainly should suit the age of the students and reflect students' higher cognitive processes:

... it is expected for teachers to give assignments which help students to resolve various problem situations, verify knowledge practically, encourage students to seek additional literature and to collect information for a variety of projects, etc.... (Upatstvo - Guidance, 2013, p. 2) 
In this sense, the Guidance should be of a great benefit to the developers of the Curriculum, teachers and textbook writers. The Guidance sets out four criteria on determining the type of homework: 1. According to the general objective, the Guidance provides homework assignments for continuing the work in class (to determine the new material that has been previously treated) and homework as an introduction to new teaching unit (to introduce students to the new theme for learning the material that is not treated yet); 2 . According to the didactic purpose, the Guidance provides homework assignments for reproducing the material from the class (they should be avoided), homework for applying knowledge in new situations which place students in active relationship (for example, to find new examples of rule that was studied in class) as well as homework for systematization of processed teaching material from one or several sections (it should be noted that other didactic purposes are not listed, so homework is considered only in relation to these two purposes and we are not getting into the analysis of other purposes); 3 . According to the technique of working out, the Guidance provides oral homework, written homework assignments, practical homework assignments, combined homework assignments; 4 . According to the number of students in solving homework assignments, Guidance provides individual and group homework assignments (Upatstvo - Guidance, 2013, pp. 4-5).

According to the Guidance, homework is an activity that distinguishes the independent work of students through which they shall determine the acquired knowledge and develop a sense of responsibility towards learning. This is an important requirement for their further self-education. Students' skills of reasoning and thinking are developed by doing homework, their self-esteem increases, their creativity and imagination are stimulated and so on. It is especially important that students become more aware of their knowledge (Upatstvo Guidance, 2013, pp. 5-6).

A survey of foreign literature towards the role of homework in the formative assessment of students' achievements indicates that there is a significant number of researches on this topic. The reason for this is simple: the developed countries have implemented the formative assessment for a very long time. From this survey it can be noted that researchers have not quite equal insights of the role of homework in the formative assessment.

At the one side, a group of researches claims that the correlation between the homework and the students' achievements is not so significant. For example, Wiggins (2013) even claims that if the homework is assigned only ones and the student cannot use the teacher's feedback in order to improve himself later on the same activity, that homework is a tool for summative and not for formative assessment.

At the other side, a group of researchers suggests that the correlation between homework and students' achievements is of a great importance. For example, Boston (1998) refers to Blake and William (1998) that homework is an activity for formative assessment if the teacher gives constructive feedback for the homework and directions for its improvement. Homework assignments contribute to train students for independent work, active and critical attitude to work and develop a sense of responsibility among students. This gradually leads to the preparation of their self-education. Cooper, Robinson, and Patall (2006) also confirm that the homework affects the students' achievements. Homework assignments contribute to the development of independence among students and to the acquirement of work habits. They assist in developing higher cognitive processes and in reflection of students' conclusions. They provide information for the teacher about the acquired knowledge of students, which is the basis for giving useful feedback that guides their learning and contributes to the promotion of their achievements. Darn (2007) claims that homework helps students to increase their understanding and motivation, develops the students' habits for independent learning and the skills for problem solving. According to Darn, the homework has to be useful for the students, important for learning, interesting and different. It has to take into account the individual styles of students' learning and to be close to the problems in the real life. Christopher (2007/2008) suggests that the homework as a tool for formative assessment has changed her classroom in a large extent. She compares the students with sportsmen and indicates that homework helps students to practice and to improve their achievements. Craft (2008) claims that the homework meets the standards of the formative assessment and it helps the students' achievements to be improved. Homework assignments develop students' research potential to solve problems, encourage creative and critical thinking. 


\section{Research Methodology}

Several research questions arise from the paper's purpose: How much the Macedonian language curriculum and course textbooks for primary education emphasize the importance of homework assignments? Is the number of homework assignments in textbooks (in the domain Language) enough? Are homework assignments interesting for students? How much the type of assignment allows students to develop higher cognitive processes and improve their achievement, and teachers to direct their learning and provide constructive feedback? To fulfil the goal of the paper and to answer the research questions, we conduct research with the qualitative paradigm (content analysis) and descriptive design. The methods for processing the data and making scientific conclusion are analysis and synthesis. The sample consists of the Macedonian language curriculum and textbook for a ninth grade of nine years of primary education in Macedonia (Velkoska \& Jovanovska, 2010). The type of homework and its characteristics are determined by the Guidance for homework made by the Bureau for Development of Education of RM. The levels of cognitive processes developed with homework assignments are determined by the Bloom's Taxonomy. At first, there is an analysis of the Macedonian language curriculum for ninth grade of nine-year primary education, approved by the Bureau for Development of Education and the Ministry of Education and Science regarding the notions it contain about the role of the homework assignments. Then, there is an analysis of Macedonian Language course textbook for the nine-year primary education, approved by the Ministry of Education and Science, regarding the criteria for the homework assignments given in the Guidance.

\section{Results and discussion}

Ninth grade is the period when students are already in the stage of adolescence and working with them is a real challenge for the teacher. Considering the fact we are talking about the final stage of their primary education, it is understandable that teachers give the students more complex tasks and activities. Accordingly, there should be no doubt that the homework is necessary especially during this period. Students at this age, spend most of the time at home in front of the computer. A reasonably creative and proficient teacher, who assigns homework which ought to be produced in electronic form, is more likely to spend students' time more effectively. But it seems that electronic homework assignments, at least regarding the educational system of the Republic of Macedonia have not yet received the attention they require, for our long-standing practice shows that older teachers do not practice electronic homework, because they do not handle computers in teaching well, and that in the case of younger teachers, although they are computer literate, there are no electronic homework assignments.

The teacher is obliged to keep records on the implementation of homework in order to get feedback from students that will help to guide students' learning (to highlight the positive aspects of their homework, to increase the self-esteem of students, to encourage their creativity etc.). The feedback will also improve his work and he should try to find creative assignments for students. Teachers' records increase the sense of responsibility among students. Otherwise, homework may lose its role as an important tool for assessing students' achievement. Our practice shows that the homework assignments aren't paid the attention they should and that it is a common practice that the more solid student takes records of homework. This is reduced to a simple number on which student has and which does not have homework and this certainly affects the reduction of students' interest for doing homework and ignorant behavior. Therefore the benefits from the homework for both, the students and the teachers are lost.

\subsection{The Curriculum for the ninth grade}

In the Macedonian language curriculum for the nine-year primary education (the language domain consists of 50 classes), the following general purposes are given: to establish and expand the knowledge about the codification of Standard Macedonian language; to accentuate domestic and foreign words in a proper way; to distinguish and properly use complex verb forms; to distinguish and properly use immutable words (particles exclamations, modal words); to differ complex clauses within the complex sentence; to distinguish functional styles; to use different Macedonian dictionaries; to use punctuation and orthographic marks in a proper way. 
Further, in the Macedonian language curriculum (language domain) the teaching content and objectives for each of the content, activities, and methods of realization of the given instructional content are noted. Within the activities and methods for the teaching content, exercises that correspond to the general and specific objectives are given (Nastavna programa - Curriculum, 2009, pp. 6-8). Of course, the teacher can use part of the planned exercises in the Curriculum as homework, but the conclusion remains that the term homework is not explicitly mentioned in the Curriculum.

It is interesting that in the area of the Curriculum devoted to the assessment of students' achievement (Nastavna programa - Curriculum, 2009, pp. 17-18), formative assessment and feedback for students' achievement are recommended. It is suggested that this can be achieved by multiple assessment methods, including homework.

\subsection{Macedonian language textbook for ninth grade}

The textbook for the subject Macedonian language for ninth grade has 172 pages, 40 of which put emphasis on the domain Language. This domain has 25 teaching units, and only seven of them have homework.

A) Regarding the teaching unit for the stress on the foreign words, there are two homework assignments in the textbook (Velkova \& Jovanovska, 2010, p. 15). The first homework assignment requires the students to rewrite the foreign words from an excerpt of a text (the story "Thief" [Kradec], D. Solev) and to put stress on them. So, basically the first homework includes two tasks, the first one is to identify the foreign words in the text, i.e. to recognize all of them, and after that to put stress on them. Regarding the second homework, the students are given around ten words and they should again put stress on them. If we take into consideration the criteria in the Guidance, it can be seen that both homework assignments are designed to make the students continue what they have already worked during the class, i.e. acquire that what has been learned during the class. Regarding the didactic purpose, those homework assignments can be used for applying, but also for the systematization of the knowledge (there are not any other teaching units related to the stress in the domain language to the end of the textbook).

According to the technique being used, they are written homework assignments, and according to the number of the students which are involved in completing them they are individual homework assignments. If we put those assignments in the context of the Bloom's Taxonomy certain dilemmas arise regarding the different interpretation of the level apply, especially when it comes to the notions new situation, familiar context and unknown context which are connected to the explanations of this level (Januševa \& Jurukovska, 2017). Thus, do the newly given words represent the new situation in the school context or does that new situation imply correctly stressing the words in the everyday life and in the workplace? How should the notions context and unknown context be understood? Having in mind these dilemmas, our statement that the homework assignments in the paper relate to the level apply of the Bloom's taxonomy should be taken with certain doubt. The first part of the first homework assignment refers to the level understanding, and the second part of the assignment refers to the level apply, because the students should first identify the foreign words, and after that, they should stress them. The second homework assignment refers to the level apply of the previously acquired knowledge. Regarding the first homework assignment, it should be mentioned that some of the foreign words in the text can be easily identified as foreign: portable, corrections etc. Some of the foreign words have entered our language a long time ago, for example, machine, fridge, batteries, coffee etc., and they are not considered as foreign words anymore. According to that, the first part of the homework assignment (the identification of the foreign words in the text), may not be realized completely, which means that the students' understanding of the foreign words may not be developed completely too.

B) Regarding the teaching unit for past simple tense (perfect and continuous) the textbook has only one homework assignment. It requires the students to write five sentences referring to this tense according to a given photo of a basketball game (Velkova \& Jovanovska, 2010, p. 17). The criteria in the Guidance show that it is a 
homework assignment that make the students continue the work from the lesson (acquiring what they worked in the class). Regarding the didactic purpose, it is a homework assignment for applying the knowledge, but also for systematization of the knowledge, (there are not any other teaching units related to this tense in the domain language to the end of the textbook). According to the technique being used, it is a written homework assignment, and according to the number of students which are included in completing it, it is an individual homework assignment. Bloom's Taxonomy reflects the levels understanding and applying of the knowledge.

C) The teaching unit for future tense has only one homework assignment. It requires the students to rewrite sentences from different texts in the textbook in which the verb forms are in future simple tense (Velkova \& Jovanovska, 2010, p. 19). The criteria in the Guidance show this homework assignment asks the students to continue the work from the lesson (acquiring what they worked on the class). Regarding the didactic purpose, it is a homework assignment for applying of the knowledge, but also for systematization of the knowledge (there is not any other teaching unit related to this tense in the language domain to the end of the textbook). According to the technique being used it is a written homework assignment, and according to the number of students which are included in doing it, it is an individual homework assignment. As in the previous two cases, this homework assignment belongs to the levels understanding and applying of the knowledge of Bloom's Taxonomy.

D) As for the teaching unit for interjections, there are three homework assignments. One of them requires the students to write sentences with the interjection Pst (Hush! Silence), in which feeling and purpose should be expressed and one sentence which expresses paying attention to someone. The second homework assignment requires the students to write sentence with the interjections: of, lele, ah, ua (oh, ouch, oh dear,) to express different feelings. The third homework assignment requires the student to find the most appropriate interjections in six given sentence, like in the following example: Deteto padna vo rekata [The child fell into the river] - Plas, deteto padna vo rekata (Shlap, the child fell into the river) (Velkova \& Jovanovska, 2010, p. 25). All three homework assignments, according to the criteria in the Guidance show that they are homework assignments with which the students continue the work from the class lesson (acquiring what they worked on the class). Regarding the didactic purpose, they are for homework assignments for applying, but also for systematization of the knowledge (there are not any other teaching units related to the interjections in the domain language to the end of the textbook). According to the technique being used it is a written homework assignment, and according to the number of students which are included in doing it, it is an individual homework assignment. Bloom's Taxonomy reflects the levels understanding and applying of the acquired knowledge.

E) Regarding the teaching unit for complex sentences expressing cause and effect, there are two homework assignments in the textbook. The first homework assignment requires the students to rewrite the complex sentences expressing cause and effect from a short text (written by another student). In the second assignment, the students should write five complex sentences expressing cause and effect by looking at a given photo of two dolphins jumping in a pool, people sunbathing and taking photos (Velkova \& Jovanovska, 2010, pp. 33-34). Having in mind the Guidance, it is obvious that all these are homework assignments with which the students continue the work from the class lesson (acquiring what they worked on the class). Regarding the didactic purpose, they are homework assignments for applying and for systematization of the knowledge because there is not any other teaching unit related to this tense in the domain language to the end of the textbook. According to the tecnique being used it is a written homework assignment, and according to the number of students which are included in doing it, it is individual homework assignment. Bloom's Taxonomy reflects the levels understanding and applying of the acquired knowledge.

F) For complex sentences expressing manner there are three homework assignments in the textbook. In the first, students need to write one modal sentence using conjunctions: bez da, kako da, nebare, božem [without, how to, though, allegedly]. In the second task, students are asked to indicate complex sentences expressing manner in a text (passage from "The last flight of the visiting bird" - [Posledniot let na pticata silica] by B. Varošlija). The third assignment is to write a composition in which students should narrate the discussions led during the class (Velkova \& Jovanovska, 2010, p. 40). From the instructions in the textbook, it is clear that the 
third homework has no link with complex sentences expressing manner and this assignment is not taken into consideration in the analysis. The directions of the Guidance indicate that both homework assignments are assignments for continuing the work of the class. Didactic aims show that these are homework assignments for implementation and systematization of the knowledge, because by the end of the teaching content from the domain language, students do not get in touch with the teaching units devoted to this type of sentences. In terms of the technique of making homework assignments, it is obvious that those are written homework, and considering the number of students who need to resolve they are individual homework assignments. Bloom's Taxonomy shows that homework assignments reflect the understanding and application levels.

G) Last homework is given within a unit for complex sentences expressing a purpose. There is an excerpt from the text "Unextinguished Wishes" - [Neizgasnati želbi] by T. Georgievski which contains different types of complex sentences. It requires the students to prescribe subordinate clause and to determine their type (Velkova \& Jovanovska, 2010, p. 42). In the instruction for doing homework in the textbook, there are no other explanations. But the instruction for students to prescribe subordinate clause is wrong, namely, the complex sentence usually consists of a main clause, which in appearance is an independent and a subordinate clause which is dependent. Therefore, it is correct to ask the students to rewrite dependent clause. The requirement to determine the type of the sentences is not correct also, because in the first part of the assignment it has already been said that subordinate clause should be prescribed. Hence, in fact, the requirement in the homework assignment is to prescribe different complex sentences and to determine their type. Probably the intention of the authors is to make systematization of knowledge of students of all kinds of complex sentences previously studied through this homework. The Guidance shows that it is homework for continuing the work from the class or for gaining the knowledge. According to the didactic objectives it is homework for application and systematization of the knowledge. The techniques of homework's preparation relate to written homework, and according to the number of students who should do it, it is an individual homework. Bloom's Taxonomy shows that, as in previous cases, this homework reflects the levels understanding and application.

The analysis shows that despite the importance of homework for formative assessment of students' achievement, it did not get proper attention neither in the Macedonian language curriculum of ninth grade in nine-year primary education nor in Macedonian language course textbook for the nine-year primary education.

Namely, in the Curriculum, homework is mentioned only once in the context that it should be a necessary tool to implement formative assessment, but other directions are not given. This situation, of course, is reflected in the quality and number of the homework assignments in the textbook. Without appropriate recommendations in the Curriculum, textbook authors freely and voluntarily decide on the number of homework assignments included in the textbook and for their quality. Considering the textbook is the primary teaching tool, it implies that teachers have the freedom to decide on the type of homework they will give, as well as whether they will assign homework to students at all. The lack of activities related to homework assignments has a negative impact primarily on training the student for independent work and the quality of the acquired knowledge. These results are not in accordance with the findings of Cooper et al. (2006) and with the directions of the Guidance. In this case, the teacher is not able to get valuable feedback on how students manage to master the material which he has taught. Also he is not even able to give feedback to direct the student learning and enhance their achievements. These findings are not in correlation with the Wiggins's research (2013) and the Guidance and they point out the significant role of the constructive feedback regarding the homework. This behavior of the persons responsible for writing the Curriculum leads to unjustified neglecting of the role that homework has. It also leads to a situation in which, during the teaching process, students are deprived of the opportunity for self-evaluation of their achievements and to develop responsible, active and a critical attitude to work. Again, these results oppose the Craft's research (2008) and the Guidance.

The analysis of Macedonian language course textbook for the nine-year primary education shows that regarding the anticipated number of classes in the language domain, there is an insignificant number of homework assignments. The textbook contains 25 teaching units from the language domain and only for 7 of 
them homework assignments are given.

Since the textbook does not contain additional information regarding homework, it can be noticed that homework is not present in every 25 teaching units of the language domain. There are only 7 homework assignments. Furthermore, all seven homework assignments are continuing the work in class or refer to absorbing the material that the teacher has taught. So the impression that homework activities are associated only with the end of one lesson is wrong. It is obvious that in the Textbook there are not homework assignments that function as the introduction to the new teaching content. Therefore, students are not able to see that activities related to homework can be connected with the beginning of a lesson. The absence of homework assignments that represent an introduction to the new unit greatly affects the development of research skills of students' critical and creative thinking, problem-solving and so on. These results are not in accordance with the Christopher's research (2007/2008) ant the directions in the Guidance. The analysis shows that, despite the directions in the Guidance, the didactic purpose of homework is not fully implemented because all seven tasks are related to the very simple application of knowledge. In the homework assignments most of the pupils are entitled, on the basis of what the teacher taught, to put a stress on proper place in given words, to write a certain kind of complex sentences according to a photo, to prescribe a certain kind of complex sentences from a text, to write complex sentences with given connectors, to write sentences with exclamations given and so on. Considering the fact that the texts are short, characteristic conjunctions of complex sentences are evident, so students do not have the opportunity to develop research dimension, solve a problem, analyze, evaluate and so on.

Homework assignments also refer to the systematization of the comprehended material because till the end of the teaching content in the domain language, students do not meet with the 7 teaching units in the textbook any more. This puts in question the directions in the Guidance and makes us accept the insight of Wiggins (2013) that these homework assignments are meant for summative and not for formative assessment. One of the necessary conditions for good homework is that it contains elements of something new, something that students have to apply in a new situation (Upatstvo - Guidance, 2013, p. 4). This direction from the Guidance brings certain dilemmas, because it is not specified to what the new elements should refer, it is not specified which situation is considered to be newly created. So, whether it is a new situation if homework is prepared at home, or, a new situation is that the problem is implemented in a new context. This is linked to dilemmas related to the level implementation by the Bloom's Taxonomy and these dilemmas are indicated in the work of Januševa and Jurukovska (2017). However, analyzed homework assignments rarely contain elements of something new, except in the first homework which requires the rule of emphasis on the third syllable to be applied to new words. The third assignment in the teaching unit for exclamations is a little unclear. This is incompatible with the Guidance, which suggests that assignments that do not have clear and explicit requirements should be avoided (Upatstvo - Guidance, 2013, p. 6).

The analysis shows that in terms of the technique of doing homework, all seven homework assignments are written and they determine the level of comprehension of the material for which the teacher has taught. This result opposed the Darn's research (2007) who claims that the homework assignments should be different. Although written homework assignments have their advantages, for example, using the standard Macedonian language, taking into consideration the aesthetic look of writing, organization of writing, proper use of punctuation, etc., it is not good to practice them constantly. That creates monotony and reinforces the view that homework should be written at home, in a separate notebook for homework. The analysis shows that within the written assignments, electronic homework assignments are not present. Electronic homework can motivate students to a large extent regarding that most of the time they spend in front of the computer. It is obvious that practical and combined homework in the Textbook are not presented. This kind of assignments can include students in project activities and they can encourage research and management skills of students, develop creative and critic opinion, develop higher cognitive processes, set students in authentic situations, and contribute to constructive feedback. By using only the written homework assignments, actually the same method of work is used and several aspects of student learning are not being taken into account. 
The analysis finds that in terms of the number of students who need to resolve the homework, all seven homework assignments are individual. The individual homework is very important because they develop the autonomy of the students and their responsibility towards work in general. That contributes to the moral characteristics of students as responsible and helpful persons in the larger community and society and is in accordance with the mentioned research. However, the constant individual work can also cause monotony among students. The absence of group homework does not give students the opportunity to cooperate, to jointly explore, to solve problems, etc., and it will affect their capacity for group work in their future education. It is shown that in all seven homework in front of the students the same or similar tasks of what has been worked in class are set, i.e. in these homework assignments there is nothing new. Homework assignments are not of interest to students and they are not developmental. They are too simple and not challenging for the students, and they do not contain elements of research, creation, critical thinking, etc. This contributes their solving to be mechanically and formally and does not encourage higher thinking processes among students. This is not in correlation with the Darn's findings (2007) that the homework assignments should be closely related to the real life problems. Although all seven homework assignments are correlated with teaching content, they are not too long, they do not take too much free time and do not cause additional costs to the family and this is in accordance with the Guidance (Upatstvo - Guidance, 2013, p. 6). Yet these homework assignments do not encourage the research and learning, do not encourage the creativity of the students and their imagination and do not encourage discussion in class. These findings are not in correlation with the directions in the Guidance. Furthermore, although the Guidance emphasizes that students should choose homework assignments (Upatstvo - Guidance, 2013, p. 6), the textbook shows that the students cannot choose, but they should do all assigned tasks. In terms of feedback that the teacher should give to students, analysis shows that it comes down to whether it is true or false homework and does not provide sufficient basis for guiding and learning improvement. Accordingly, if the teacher is not enough motivated and creative to prepare homework assignments that will be in function of formative assessment, homework, in a large extent, loses its role and becomes just one of the activities that are implemented formally. Homework should create a solid foundation for developing a sense among students that they can independently control their own learning process.

\section{Conclusion}

From the analysis provided in terms of research questions the following can be concluded: In the Curriculum for ninth grade homework is mentioned only once in the context of a successful implementation of formative assessment, but other directions are not given. Considering that textbooks are written based on the Curriculum, it is obvious that changes in the Curriculum and Textbooks are needed. The textbooks need explicit guidance on the importance of homework, particularly in terms of that homework provides independent work of students and increases their responsibility. In relation to the type of assignments they should focus on developing higher cognitive processes and constructive feedback. The textbook reflects the situation in the Curriculum. It means that enough attention is not spent on homework assignments. From 25 teaching units, only seven homework assignments are assigned. In all of them there is an absence of research dimension, there is a lack of inclusion of higher cognitive processes in their resolution, and lack of the ability for constructive feedback to improve and guide the students' learning. All analyzed homework assignments are meant for continuing the work of the lesson in class, for application of the gained knowledge, written and individual assignments. All of them reflect the levels understanding and application of the Bloom's Taxonomy.

The survey results are very important for the Ministry of Education and Science of the Republic of Macedonia and the Bureau for Development of Education, because these, as key factors in education should be aware of the quality of the curricula and textbooks that are approved for use. They should be careful in the selection of individuals who work on these documents. Then, the results are important for authors of textbooks which should show critical attitude of what they write, to take into account the importance of homework in the independent work of the student and constantly work on their professional development. The results are very important for teachers who also have to show critical attitude towards homework assignments given in the 
textbooks. If they estimate that they are not aimed to improve the students' learning and do not activate the higher cognitive processes of students, they should conceived quality homework assignments. These assignments should emphasize the autonomy of the students, research, creative and critical potentials, the ability for group work, the ability to adapt to different working methods etc. Finally, if we take into consideration the results of the survey, students have the most benefit from it. Quality homework involves a serious and responsible attitude of students towards it. This reduces the possibility of homework be approached formally and mechanically and increases the possibility of students to become citizens with a developed autonomy in the work.

Finally it is justified to mention that the Guidance has been written in 2013. This means that it is published three years after the publication of the analyzed textbook (currently there is no textbook in Macedonian language that was written in 2013 and after 2013). However, it does not undermine the importance of research. On the one hand, it is important for the creators of the curricula and the authors of the textbook that will be written in the future, which should take into consideration the results obtained. On the other hand, the review of the professional literature shows that before 2013 there are studies that emphasize the importance of homework, which certainly should have been considered.

\section{References}

Andrilović, V., \& Čudina, M. (1984). Psihologija učenja i nastave [Psychology of learning and teaching]. Zagreb: Školska knjiga.

Black, P., \& Wiliam, D. (1998). Inside the black box: Raising standards through classroom assessment. Phi Delta Kappan, 80(2), 139-148. Retrieved from http://www.pdkintl.org/kappan/kbla9810.htm

Boston, C. (2002). The concept of formative assessment. Retrieved from http://www.vtaide.com/png/ERIC/Formative-Assessment.htm

Bureau for Development of Education. (2013). Upatstvo za načinot i formata na podgotvuvanje, planiranje, zadavanje, realiziranje i sledenje na domašnite zadači na učenicite vo osnovnoto obrazovanie [Guidance for the manner and form of preparing, planning, giving, realizing and following the home works of the students form the primary education]. Skopje: Bureau for Development of Education. Retrieved from http://bro.gov.mk/docs/aktuelno/Upatstvo\%20za\%20domasni\%20zadaci.pdf

Christopher, S. (2007/2008). Homework: A few practice arrows. Educational Leadership, 65(4), 74-75.

Cooper, H. (2006, December). December, 2006 interview with Dr. Harris Cooper, author of "the battle over homework" (N. Sellers and S. Adams, interviewers). Audio main interview. Retrieved from https://lenny-homework.wikispaces.com/file/view/battle+over+homework+interview.pdf

Cooper, H., Robinson, J. C., \& Patall, E. A. (2006). Does homework improve academic achievement? A synthesis of research 1987-2003. Review of Educational Research, 76(1), 1-62. https://doi.org/10.3102/00346543076001001

Craft, H. (2008). Common sense and homework. Retrieved from https://www.naesp.org/resources/1/Principal/2008/S-Op62.pdf

Darn, S. (2007). Teaching English homework. Retrieved from https://www.teachingenglish.org.uk/article/homework

Januševa, V., \& Jurukovska, J. (2017). Formative assessment in teaching the Macedonian language (primary education in R. Macedonia). International Journal of Assessment Tools in Education, 4 (1), 54-78.

Januševa, V., \& Talevski Dimitrija, J. (2015). Aspekti na ocenuvanjeto [Aspects of the assessment]. Bitola: Faculty of Education.

Kamčevska, B. (2006). Razvoj na programi i strategii za avtoindividualizacija na decata [Development of programs and strategies for auto-individualization of the children]. Skopje.

Ministry of Education and Science. (2009). Nastavna programa po makedonski jazik za devetto oddelenie na devetgodišnoto osnovno obrazovanie [Macedonian language teaching curriculum for ninth grade of the nine-year primary education]. Skopje: Ministry of Education and Science and Science of the Republic 
of Macedonia, Bureau for Development of Education. Retrieved from

http://www.bro.gov.mk/docs/makedonski_jazik.pdf

Stevanović, M. (2001). Didaktika. [Didatics]. Rijeka: Express digitalni tisak.

Velkova, S., \& Jovanovska, S. (2010). Makedonski jazik za VIII oddelenie [Macedonian language course textbook for eight grade]. Skopje: Ministry of Education and Science of the Republic of Macedonia. Retrieved from http://www.e-ucebnici.mon.gov.mk/pdf/Makedonski_8_velkova.pdf

Vilotijević, M. (1999). Didaktika II [Didactics II]. Beograd: Naučna knjiga.

Wiggins, G. (2013). Authentic education. Using homework as formative assessment. http://www.teachthought.com/pedagogy/assessment/using-homework-as-formative-assessment/

Wilson, L. O. (2013). The second principle. Anderson and Krathwohl - Understanding the new version of Bloom's Taxonomy. Retrieved from http://thesecondprinciple.com/teaching-essentials/beyond-bloom-cognitive-taxonomy-revised/ 
Januševa, V., Pejčinovska, M., Talevski Dimitrija, J., \& Merkovska, M. 